\title{
Original
}

\section{Epithelial Cell Differentiation from Human Induced Pluripotent Stem Cells Using a Single-Cell Culture Method}

\author{
Taku Futenma, Yasunori Akiyama, Sho Tanaka, Masaki Honda and Taku Toriumi
}

Department of Oral Anatomy, School of Dentistry, Aichi Gakuin University, Nagoya, Japan

(Accepted for publication, January 25, 2021)

\begin{abstract}
The conventional culture method of human induced pluripotent stem cells (hiPSCs) has been performed in colony cultures using feeder cells, such as mouse embryonic fibroblasts, which require setup times and procedural complexity, a potential risk of transmission of animal pathogens. Besides, the colony culture exhibits slow growth rate and often give rise to heterogeneous cellular states. However, developing technical methodologies of hiPSCs remains pivotal for use in medical applications and research. Here, we investigated whether hiPSCs passaged and expanded as single cells under feeder-free conditions could differentiate into ectodermal-epithelial cells as a source of cells for future regenerative medicine research. First, an hiPSC line 253G1 was cultured in colonies maintained on feeders and subsequently transferred to a single cell on feeder-free. hiPSCs were then cultured as single cells for 28 days in an induction medium supplemented with retinoic acid, bone morphogenetic protein 4, and N2 supplement for epithelial cell differentiation. The expression of epithelial markers, tumor protein p63 (P63), cytokeratin (CK) 18, and CK14 in induced cells was evaluated over time using real-time polymerase chain reaction, western blotting, and immunocytochemistry. Results showed that hiPSCs cultured as single cells expressed pluripotency markers, as evidenced by colony cultures maintained on feeders. On day 7 post-induction, hiPSCs assumed a cobblestone-like morphology in the epithelial induction medium. Induced cells displayed increased mRNA expression levels of CK18, P63, and CK14 during the 28-day induction period. Furthermore, the expression levels of CK18, P63, and CK14 were detected via western blotting and immunocytochemistry. Our findings suggest that hiPSCs cultured as single cells could be differentiated into epithelial cells.
\end{abstract}

Key words: Epithelial cell differentiation, Human induced pluripotent stem cells, Single-cell culture method, Feeder-free

\section{Introduction}

Epithelial tissues cover the body, cavity organs, and glands to function as barriers ${ }^{1,2)}$. Epithelial cells exhibit two polarities to form epithelial tissues: one is facing body or organ surface (the apical surface) and the other is facing connective tissues (the basal surface) ${ }^{1,2}$. While gastrulation occurs, cells are differentiated into three germ layers (ectoderm, mesoderm, and endoderm), followed by epithelial invagination into the primitive streak. The invaginated epithelium then forms the primitive gut, leading to the formation of the digestive tract, pancreas, liver, etc., and becomes the endoderm, leaving the ectoderm on the outer layer of the embryo ${ }^{3,4)}$.

Regenerative therapy is aimed at stimulating recovery from disease, injury, or aging through approaches such as the application of stem cells and/or progenitor cells to repair damaged tissues or organs and restore function ${ }^{5,6)}$. An ideal cell source should be easily obtainable and expandable in vitro $^{7}$. For example, as cell sources for epithelial tissue engineering, autologous cultured epidermis or oral mucosal epithelial cells have been applied in the clinical setting to treat burns ${ }^{8,9)}$ or corneal disorders $^{10,11)}$, respectively. However, the typical culture conditions for transplantable epithelial cells commonly require murine $3 \mathrm{~T} 3$ feeder cells and

Correspondence to: Dr. Taku Toriumi, Department of Oral Anatomy, School of Dentistry, Aichi Gakuin University, 1-100 Kusumoto-cho, Chikusa-ku, Nagoya, Aichi 464-8650, Japan; Phone: +81-52-751-2561; Fax: +81-52-7525988; E-mail: toriumi@dpc.agu.ac.jp an addition of fetal bovine serum to the culture because it is difficult to prevent pathogen transmission or infection when using animal-derived materials ${ }^{12)}$. In addition, a sheet derived from autologous retinal pigment epithelial cells was transplanted in the early $2000 \mathrm{~s}^{13-15}$, however, the procedure of harvesting the retinal pigment epithelial cell sheet is invasive and complex, and is a high risk of severe bleeding and retinal detachment ${ }^{15-19)}$. Furthermore, for tooth regeneration, epithelial cells should ideally be combined with mesenchymal cells to mimic the tooth development process. To date, studies of tooth regeneration have revealed that at the cap stage of embryonic day 14 or 14.5 mice, the application of murine tooth germ cells produced regularly-shaped teeth ${ }^{20-22}$. However, porcine postnatal tooth germ cells applied during the late bell stage generated unusually shaped dental tissues ${ }^{23)}$. These results suggest that embryonic tooth germ cells at the cap stage retain their tooth-forming potential; however, using embryonic tooth germ cells is not feasible for clinical applications because of ethical issues. Thus, more suitable cell sources for applications in epithelial tissue engineering for regenerative therapy research are needed.

In 2006, Takahashi and Yamanaka reported the successful derivation of induced pluripotent stem cells (iPSCs) from mouse embryonic and adult fibroblasts ${ }^{24}$, followed by the generation of human iPSCs (hiPSCs) from human dermal fibroblasts ${ }^{25)}$. Overcoming potential ethical issues associated with the use of embryonic stem cells (ESCs), iPSCs are derived from various somatic cells and can differentiate into the cell types 
of all three germ layers ${ }^{25-28)}$. Thus, hiPSCs have broad applicability in studies of disease mechanisms, drug screening, and regenerative medicine ${ }^{29-31)}$. Conventional iPSC culture has been performed in colony cultures using feeder cells, such as mouse embryonic fibroblasts (MEFs). However, long setup times are required, which increases the procedural complexity $^{32}$. Furthermore, human ESCs (hESCs) cultured on MEFs express an immunogenic non-human sialic acid on their surface, which may induce an immune response upon transplantation ${ }^{33)}$. To prevent the transmission of animal pathogens and the subsequent induction of an immune response, the clinical translatability of hiPSCs has recently led to improvements in the development of fully defined and xeno-free media and coating matrices for pluripotency cell (PSC) cultures ${ }^{34)}$. Few single-cell passaging methods have been reported, in which cells are cultured upon the addition of Rho-kinase inhibitors to improve the single-cell plating efficiency ${ }^{35-37)}$. However, the final cellular products of these methods include colony-type hESCs ${ }^{37,38)}$. Single cell-type culture, which prevents colony formation, is preferable because colony cultures result in slower expansion and cellular heterogeneity ${ }^{35)}$. Furthermore, novel medium and coating material supporting single-cell passaging and the expansion of human PSCs (hPSCs) as single-cell cultures in a feeder-free and defined environment have been developed ${ }^{34,39-41)}$.

Recently, Cellartis ${ }^{\circledR}$ DEF-CS ${ }^{\mathrm{TM}} 500$ culture medium (DEF-CS medium) was shown to be very efficient for use in single-cell cloning ${ }^{34)}$ and genome editing ${ }^{40)}$. iPSCs cultured in DEF-CS medium are passaged as single cells and expand as a homogeneous monolayer, thereby maintaining pluripotency with a stable karyotype ${ }^{39,41)}$. The efficient and scalable culture methods of hiPSCs and large-scale production of differentiated cells are prerequisites for regenerative therapy research and subsequent applications ${ }^{42}$. This method was applied to pancreatic epithelium ${ }^{43)}$ and neural differentiation ${ }^{44)}$; however, to the best of our knowledge, the differentiation of such PSCs cultured as single cells into surface ectodermal cells (hereafter, ectodermal-epithelial cells) has not been reported. Therefore, this study aimed to evaluate the feasibility of using single-cell and feeder-free cultures of hiPSCs to support differentiation into ectodermal-epithelial cells.

\section{Materials and Methods \\ Culturing of hiPSCs on feeders}

We purchased pregnant Institute for Cancer research (ICR) mice (n $=2$, Chubu Kagaku Shizai Co. Ltd., Nagoya, Japan) and generated MEFs from 12-day mouse embryos with reference to a previously described method ${ }^{24)}$. This animal experiment was approved by the Animal Care and Use Committee for School of Dentistry, Aichi Gakuin University (approval number AGUD420). Animal care and experimental procedures were conducted in accordance with the Regulations on Animal Experimentation at School of Dentistry, Aichi Gakuin University.

The hiPSC line $253 \mathrm{G1}^{45}$ ) was obtained from the RIKEN BRC through the Project for Realization of Regenerative Medicine and the National Bio-Resource Project of the MEXT, Japan. As previously reported, undifferentiated hiPSCs were cultured on mitotically inactivated MEF feeder cells in 1:1 Dulbecco's modified Eagle's medium:Ham's nutrient mixture F-12 (DMEM-F12; Sigma-Aldrich, St. Louis, MO, USA), 20\% KNOCKOUT Serum Replacement (Thermo Fisher Scientific, Waltham, MA, USA), $0.1 \mathrm{mM}$ nonessential amino acids (Thermo Fisher Scientific), $0.11 \mathrm{mM}$ 2-mercaptoethanol (Thermo Fisher Scientific), $100 \mathrm{U} / \mathrm{mL}$ penicillin, $100 \mu \mathrm{g} / \mathrm{mL}$ streptomycin, and $2 \mathrm{mM} \mathrm{L-glu-}$ tamine (Sigma-Aldrich) supplemented with $5 \mathrm{ng} / \mathrm{mL}$ recombinant human basic fibroblast growth factor (Fujifilm Wako, Osaka, Japan) ${ }^{19)}$. Cultures were maintained at $37^{\circ} \mathrm{C}$ in a $5 \% \mathrm{CO}_{2}$ incubator with daily fresh medium changes.

\section{Culturing of hiPSCs as single cells}

Cultured hiPSC colonies as described above were disrupted using TrypLE Select (Thermo Fisher Scientific) and seeded in DEF-CS medium (Takara, Shiga, Japan) at a density of $2 \times 10^{4}$ cells $/ \mathrm{cm}^{2}$ on dishes coated with COAT-1 (Takara). The medium was replaced every 1-2 days. Feeder cells were eliminated through repeated passaging. The hiPSCs were then seeded at an approximate density of $4-5 \times 10^{4} \mathrm{cells} / \mathrm{cm}^{2}$ and passaged every 3-4 days for further use. Before commencement of the experiment, the expression levels of pluripotency markers, including OCT3/4, SOX2, $K L F 4$, and $c-M Y C$, in hiPSCs cultured in colonies and as single cells were confirmed by performing polymerase chain reaction (PCR).

\section{Differentiation of hiPSCs cultured as single cells into epithelial cells}

The induction method reported by Cai et al. ${ }^{46}$, originally used to differentiate hiPSCs and hESCs cultured in colonies into epithelial sheets, was used to differentiate hiPSCs as single cells into ectodermal-epithelial cells. Prior to the execution of the experiment, to ensure the same degree of epithelial differentiation potency of hiPSCs cultured as single cells and as colonies maintained on feeders, both types of hiPSCs were cultured in an epithelial induction medium for over a period of 7 days. hiPSCs cultured in colonies maintained on feeders were used as positive controls.

The experimental design using hiPSCs cultured in single cells was as indicated in Fig. 1. First, to determine a suitable coating material for differentiation into epithelial cells, hiPSCs as single cells were seeded (4 $\times 10^{5}$ cells $/ \mathrm{cm}^{2}$ ) in pre-coated dishes with three different types of coating: Collagen IV (Corning BioCoat Cellware, Mouse collagen type IV, 354416; Corning, Bedford, MA, USA), Matrigel (Corning BioCoat Matrigel Cellware, 354601; Corning), or COAT-1 (Takara). After culturing for 1-2 days, the medium was replaced with epithelial induction medium, DMEM-F12 (Sigma-Aldrich) supplemented with 1X N2 supplement (Thermo Fisher Scientific), $1 \mu \mathrm{M}$ retinoic acid (RA; Fujifilm Wako), and $25 \mathrm{ng} / \mathrm{mL}$ bone morphogenetic protein (BMP4; Fujifilm Wako). hiPSCs were induced for a maximum of 28 days and the induction medium was replaced daily. Thereafter, the cells were observed using a phase-contrast microscope and counted for the indicated periods using a cell counter model R1 (Olympus, Tokyo, Japan). Each test was conducted in triplicate.

\section{PCR analysis}

Total RNA was extracted after cell differentiation (days 3, 7, 10, 14, 21, and 28) using the RNeasy Plus Mini Kit (Qiagen, Valencia, CA,

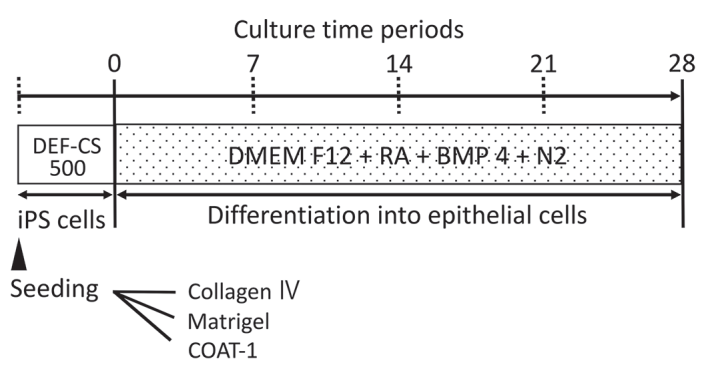

Figure 1. Schematic of the experimental protocol for the differentiation of human induced pluripotent stem cells (hiPSCs) into epithelial cells. hiPSCs were seeded on dishes coated with Collagen IV, Matrigel, or COAT-1. Following 1-2 days of culture in Cellartis ${ }^{\circledR}$ DEF-CS ${ }^{\mathrm{TM}} 500$ culture medium, hiPSCs were induced to differentiate into epithelial cells in an epithelial induction medium. 
Taku Futenma et al.: Epithelial Cells Derived from hiPSCs Cultured as Single Cells

Table 1. Sequences of primer pairs for real-time PCR

\begin{tabular}{|c|c|c|c|}
\hline Gene & Primer Sequence (5'-3') & $\begin{array}{l}\text { Size } \\
(b p)\end{array}$ & $\begin{array}{l}\text { Accession } \\
\text { Number }\end{array}$ \\
\hline \multirow{2}{*}{$\begin{array}{l}\text { Tumor protein } \mathrm{p} 63 \\
(P 63)\end{array}$} & F: TCTGTCCCAACGTGCCCATCAT & \multirow[t]{2}{*}{121} & \multirow[t]{2}{*}{ NM_001664 } \\
\hline & R: CTGCCTTCTTCAGGTTTCACCG & & \\
\hline \multirow{2}{*}{$\begin{array}{l}\text { Cytokeratin } 14 \\
(\text { CK14 })\end{array}$} & F: GACCTGGAAGTGAAGATCCGTGA & \multirow[t]{2}{*}{126} & \multirow[t]{2}{*}{ NM_000526 } \\
\hline & R: ATTGTCCACTGTGGCTGTGAGAA & & \\
\hline \multirow{2}{*}{$\begin{array}{l}\text { Cytokeratin } 18 \\
(\text { CK18) }\end{array}$} & F: GCTGGAAGATGGCGAGGACTTT & \multirow{2}{*}{119} & \multirow{2}{*}{ NM_000224 } \\
\hline & R: TGGTCTCAGACACCACTTTGCC & & \\
\hline \multirow{2}{*}{$\begin{array}{l}\text { Claudin } 1 \\
(C L D N 1)\end{array}$} & F: GTCTTTGACTCCTTGCTGAATCTG & \multirow[t]{2}{*}{144} & \multirow[t]{2}{*}{ NM_021101 } \\
\hline & R: CACCTCATCGTCTTCCAAGCAC & & \\
\hline \multirow{2}{*}{$\begin{array}{l}\text { Cadherin } 1 \\
(\mathrm{CDHI})\end{array}$} & F: GCCTCCTGAAAAGAGAGTGGAAG & \multirow[t]{2}{*}{131} & \multirow[t]{2}{*}{ NM_004360 } \\
\hline & R: TGGCAGTGTCTCTCCAAATCCG & & \\
\hline \multirow[t]{2}{*}{ OCT3/4 } & F: GACAGGGGGAGGGGAGGAGCTAGG & \multirow[t]{2}{*}{144} & \multirow[t]{2}{*}{ NM_002701 } \\
\hline & R:CTTCCCTCCAACCAGTTGCCCCAAAC & & \\
\hline \multirow[t]{2}{*}{ SOX2 } & F: GAAAGAAAGGGAGAGAAGTTTGAG & \multirow[t]{2}{*}{130} & \multirow[t]{2}{*}{ NM_003106 } \\
\hline & R: GCAAACTGGAATCAGGATCAA & & \\
\hline \multirow[t]{2}{*}{ KLF4 } & F: AAGAGTTCCCATCTCAAGGCACA & \multirow[t]{2}{*}{91} & \multirow[t]{2}{*}{ NM_004235 } \\
\hline & R: GGGCGAATTTCCATCCACAG & & \\
\hline \multirow[t]{2}{*}{$c-M Y C$} & F: CGGATTCTCTGCTCTCCTCGAC & \multirow[t]{2}{*}{199} & \multirow[t]{2}{*}{ NM_002467 } \\
\hline & R: CCTCCAGCAGAAGGTGATCCA & & \\
\hline \multirow{2}{*}{$\begin{array}{l}\text { Glyceraldehyde-3-phosphate } \\
\text { dehydrogenase (GAPDH) }\end{array}$} & F: GTCTCCTCTGACTTCAACAGCG & \multirow[t]{2}{*}{131} & \multirow[t]{2}{*}{ NM_002046 } \\
\hline & R: ACCACCCTGTTGCTGTAGCCAA & & \\
\hline
\end{tabular}

USA), following the manufacturer's instructions. RNA was extracted from the 253G1-derived neural crest cells (NCCs) as previously described $^{47)}$ and served as the negative control. RNA concentration was determined using a NanoDrop 1000 spectrophotometer (Thermo Fisher Scientific). First-strand cDNA was then synthesized from $100 \mathrm{ng}$ of total RNA and amplified using ReverTra Ace qPCR RT Master Mix with gDNA Remover (Toyobo, Osaka, Japan) per manufacturer's instructions. cDNA aliquots $(2 \mu \mathrm{l})$ were subjected to quantitative real-time PCR using the TB Green Premix Ex Taq II (Takara) on a thermal cycler (Thermal Cycler Dice Real-Time System III, Takara). Data were analyzed using LCD Software (Takara). Real-time PCR cycling conditions were as follows: 40 cycles at $95^{\circ} \mathrm{C}$ for $5 \mathrm{~s}$ and $60^{\circ} \mathrm{C}$ for $30 \mathrm{~s}$. Each real-time PCR reaction was performed in triplicate. mRNA expression levels were then determined and normalized to those of human glyceraldehyde 3-phosphate dehydrogenase $(G A P D H)$ mRNA. mRNA expression levels were also determined relative to those in undifferentiated hiPSCs using the $\Delta \Delta \mathrm{Ct}$ method. Specific primer sequences for each gene are listed in Table 1. Subsequently, few PCR amplicons were separated by electrophoresis at $50 \mathrm{~V}$ on a $2 \%$ agarose gel on Mupid-2 (Advance Co. Ltd., Tokyo, Japan).

The mRNA expression levels of induced cells from hiPSCs cultured as single cells were compared with those of induced cells derived from hiPSCs cultured in colonies maintained on feeders. After induction for 7 days, cells were harvested, and epithelial cell markers (P63, CK18, and CK14) were examined.

\section{Expression profiling of genes encoding cell adhesion molecules}

Expression profiling was performed using an array of real-time PCR primers for genes encoding cell adhesion molecules (PrimerArray Cell adhesion molecules [Human] PH003; Takara) per manufacturer's instructions. The primer array contained a mixture of 96 primer pairs for 88 genes encoding cell adhesion molecules and 8 housekeeping genes. Gene expression was quantified using the PrimerArray Analysis Tool version 2.2 (Takara).

\section{Western blotting}

Proteins were extracted using the Mammalian Protein Extraction Reagent (Thermo Fisher Scientific) per the manufacturer's instructions af- ter epithelial cell differentiation (days 3, 14, and 28). Protein concentration was determined using a BCA protein assay (Thermo Fisher Scientific) per the manufacturer's instructions. For western blot analysis, equal amounts of proteins were separated on 4-15\% Mini-PROTEAN TGX gels (Bio-Rad Laboratories, Hercules, CA, USA) and electro-transferred onto polyvinylidene difluoride membranes (Bio-Rad) for $1 \mathrm{~h}$ at $50 \mathrm{~V}$. After blocking membranes with $1 \mathrm{X}$ Tris-buffered saline (TBS) with $1 \%$ casein (Bio-Rad), they were probed for $18 \mathrm{~h}$ at $4{ }^{\circ} \mathrm{C}$ with primary antibodies, including rabbit monoclonal anti-P63 (1:500; Abcam, Cambridge, MA, USA), mouse monoclonal anti-cytokeratin (CK) 14 (1:500; Abcam), mouse monoclonal anti-CK 18 (1:500; Abcam), and mouse monoclonal anti-GAPDH (1:10,000; Thermo Fisher Scientific) antibodies. The membrane was washed with TBS with Tween 20 and then probed for $1 \mathrm{~h}$ at $25^{\circ} \mathrm{C}$ with either preabsorbed goat anti-mouse IgG H\&L (HRP; 1:1,000; Abcam) and goat anti-rabbit IgG (H+L; 1:1,000; Thermo Fisher Scientific) used as secondary antibodies. Detection was performed using Clarity Western ECL (Bio-Rad), and a Fuji LAS 4000 image analyzer was used for imaging (Fujifilm, Tokyo, Japan).

\section{Immunocytochemistry}

Induced cells were fixed with $4 \%$ paraformaldehyde in phosphate-buffered saline (PBS) and rendered permeable with $0.1 \%$ Triton X-100 (Kanto Chemical, Tokyo, Japan) in PBS. The cells were blocked using 2.5\% normal horse serum (Vector Laboratories, Burlingame, CA, USA) for $1 \mathrm{~h}$ and then incubated with the following primary antibodies: rabbit monoclonal anti-P63 (1:100; Abcam) and mouse monoclonal anti-CK14 (1:100; Abcam), or CK18 (1:200; Abcam) antibodies for $16 \mathrm{~h}$ at room temperature $\left(25^{\circ} \mathrm{C}\right)$. Isotype controls were normal mouse IgG (Fujifilm Wako) and rabbit IgG (Gene Tex, Irvine, CA, USA). The secondary antibodies, Alexa Fluor 488 goat anti-mouse IgG (1:200 for anti-CK14 antibody and 1:1,000 for anti-CK18 antibody; Thermo Fisher Scientific), and Alexa Fluor 594 goat anti-rabbit IgG (1:200 for anti-P63 antibody; Thermo Fisher Scientific), were added and incubated for $1 \mathrm{~h}$ at room temperature $\left(25^{\circ} \mathrm{C}\right)$. Cells were then counterstained with $1 \mu \mathrm{g} /$ $\mathrm{ml}$ 4',6-diamidino-2-phenylindole (DAPI; Dojindo, Kumamoto, Japan) and observed under a BZX-710 fluorescence microscope (Keyence, Osaka, Japan). To determine the percentage of epithelial marker-positive cells, CK18-, P63-, and CK14-positive and total cells were enumerated 
J.Hard Tissue Biology Vol. 30(2): 151-160, 2021

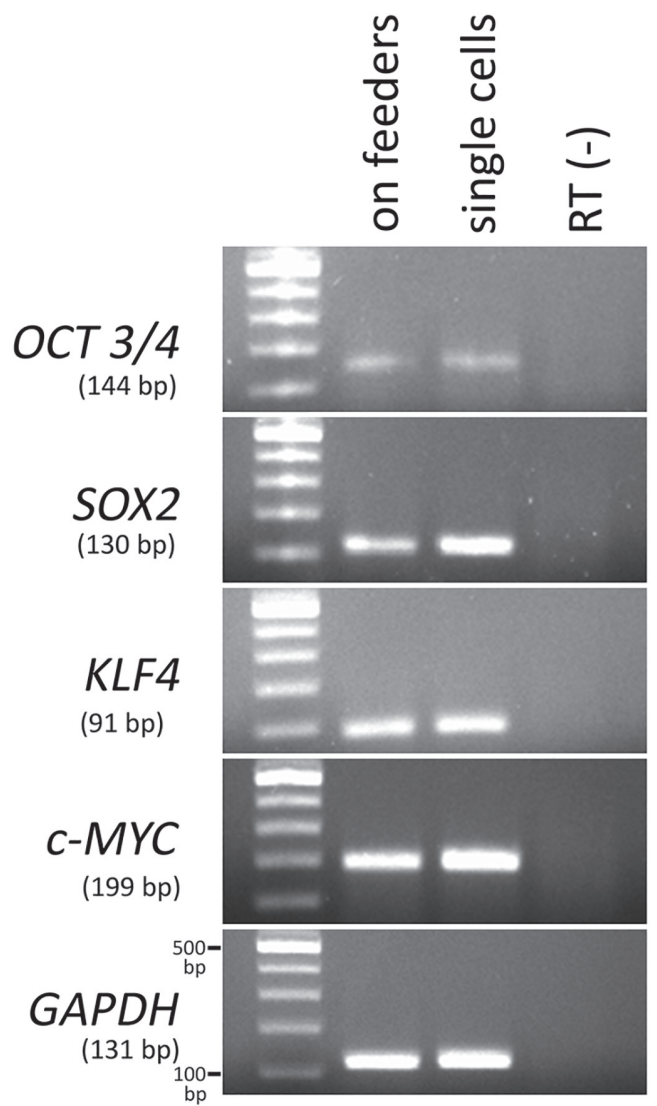

Figure 2. Expression of pluripotency markers in human induced pluripotent stem cells (hiPSCs) cultured as single cells and in colonies on feeders. hiPSCs cultured as single cells expressed pluripotency markers including $O C T 3 / 4, S O X 2, K L F 4$, and $c-M Y C$, similar to those cultured in colonies maintained on feeders. To rule out the presence of genomic DNA contamination, the same procedure was conducted without performing reverse transcription. All PCR products, except for GAPDH ( 28 cycles), were subjected to 32 cycles. RT (-): negative control.

in three randomly selected fields of view to obtain average values. DAPI-stained cells were counted to enumerate total cells. The percentage was then determined using the following equation: CK18-, P63-, and CK14-positive cells/total cells $\times 100 \%$.

\section{Statistical analysis}

Data are presented as mean \pm standard deviation (SD). Statistical analysis was performed using Microsoft Excel ${ }^{\circledR}$ for Mac (Microsoft, Redmond, WA, USA). Statistical differences were evaluated using Student's $t$-test, and $P<0.05$ was considered statistically significant.

\section{Results}

Expression of pluripotency markers in hiPSCs cultured as single cells Electropherograms of the PCR products are illustrated in Fig. 2. The expression levels of pluripotent markers, including OCT3/4, SOX2, $K L F 4$, and $c-M Y C$, were observed in hiPSCs cultured as single cells or in colonies maintained on feeders.

\section{Differentiation potential of hiPSCs cultured as single cells and in col- onies maintained on feeders}

After hiPSCs cultured in colonies (Fig. 3A, B) were maintained in the epithelial induction medium for 7 days, the induced cells displayed a cobblestone-like morphology (Fig. 3C). Thereafter, the expression levels of epithelial cell markers in induced cells derived from hiPSCs cultured in colonies on feeders and as single cells were compared. In both cases, the mRNA expression levels of epithelial cell markers in induced cells were significantly higher than those in undifferentiated hiPSCs (Fig. 4).

\section{Morphology and cell proliferation of hiPSCs cultured as single cells during epithelial cell differentiation}

Three different coating materials were prepared to induce hiPSCs cultured as single cells into epithelial cells (Fig. 1). When hiPSCs were seeded in the COAT-1-coated dishes (Fig. 5A), the cells were stably cultured without further passaging for 28 days. Cells cultured in the induction media displayed a cobblestone-like morphology, resembling that of epithelial cells, beginning on approximately day 7 of induction (Fig. 5B), and displayed a higher density after day 14 (Fig. 5C, D). In the case of hiPSCs seeded in Collagen IV-coated dishes, the cells adhered to the dish at $12 \mathrm{~h}$ (Fig. 5E). However, they detached $24 \mathrm{~h}$ after seeding (Fig. 5F). Simultaneously, hiPSCs seeded in the Matrigel-coated dishes adhered to the dish (Fig. 5G). However, all cells detached on day 6 of induction (Fig. 5H). Based on these results, hiPSCs cultured as single cells seeded on COAT-1-coated dishes clearly showed an epithelial celllike morphology and were used for subsequent experiments. We then observed cell proliferation. The number of induced cells on day 10 increased by 4.8 -fold compared to that on day 3 , whereas the cell number

\section{Undifferentiation}

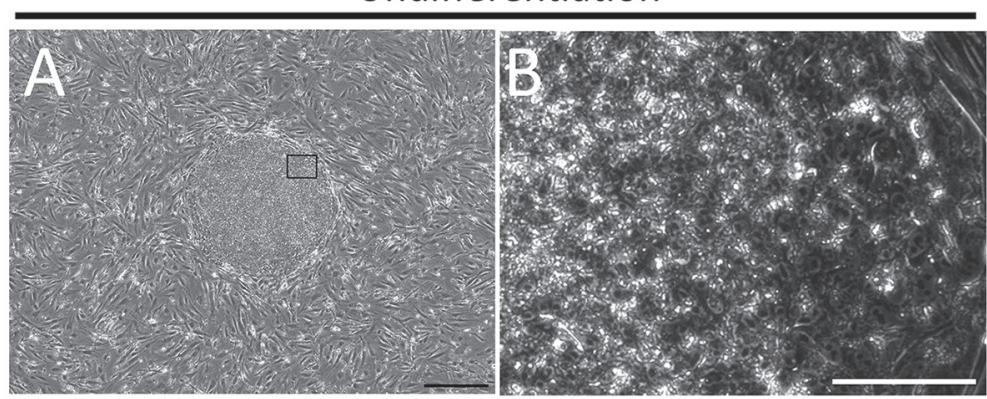

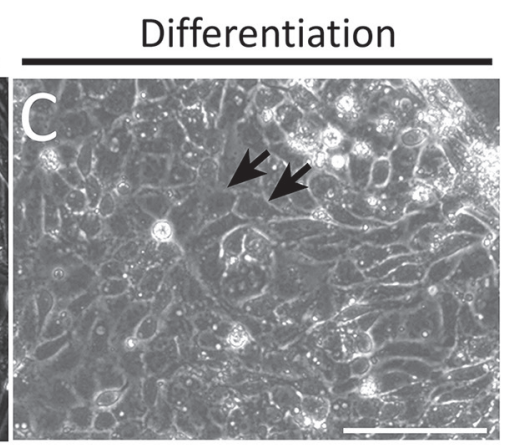

Figure 3. Phase-contrast microscopic image of human induced pluripotent stem cells (hiPSCs) cultured in colonies on feeders. (A) hiPSCs were maintained in an undifferentiated state on mouse embryonic fibroblast feeders. (B) Higher magnification of the area demarcated in (A). (C) hiPSCs cultured in an epithelial induction medium for 7 days displayed a cobblestone-like morphology (arrows). Black scale bar, 500 $\mu$ m; white scale bars, $100 \mu \mathrm{m}$. 
Taku Futenma et al.: Epithelial Cells Derived from hiPSCs Cultured as Single Cells

P63

CK18

CK14

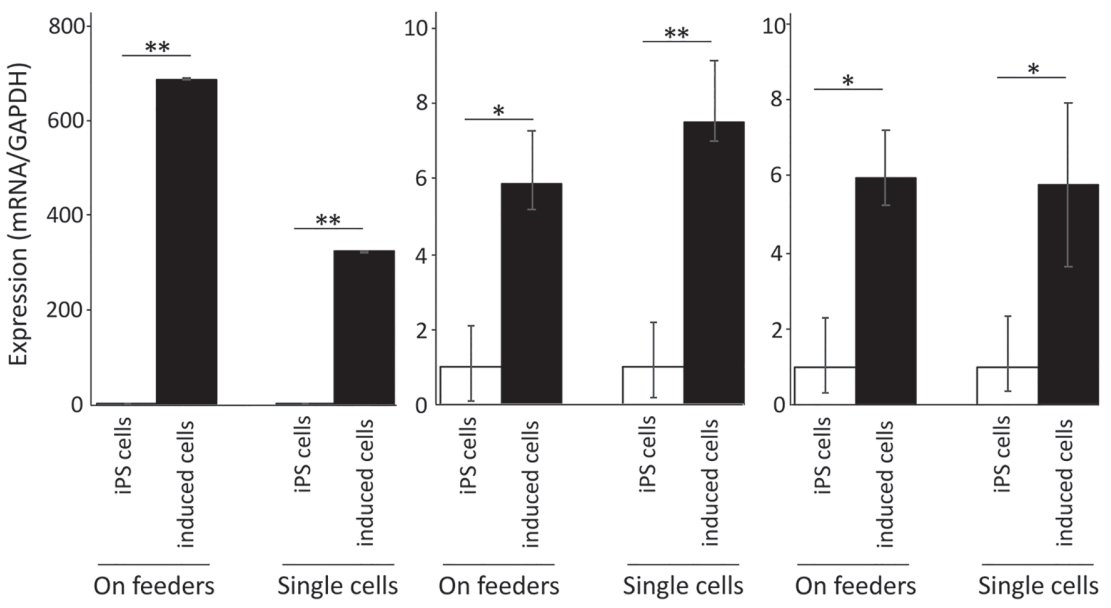

Figure 4. Expression of epithelial marker genes in human induced pluripotent stem cells (hiPSCs) on day 7 of culture in epithelial induction medium as single cells compared with that in colonies on feeders. The relative expression levels of $P 63, C K 18$, and $C K 14$ were significantly higher in induced cells than those in hiPSCs cultured as single cells, and were similar to those in colonies. GAPDH was used as an internal control. Data are represented as mean $\pm \mathrm{SD}(\mathrm{n}=3) . * P<0.05, * * P<0.01$.

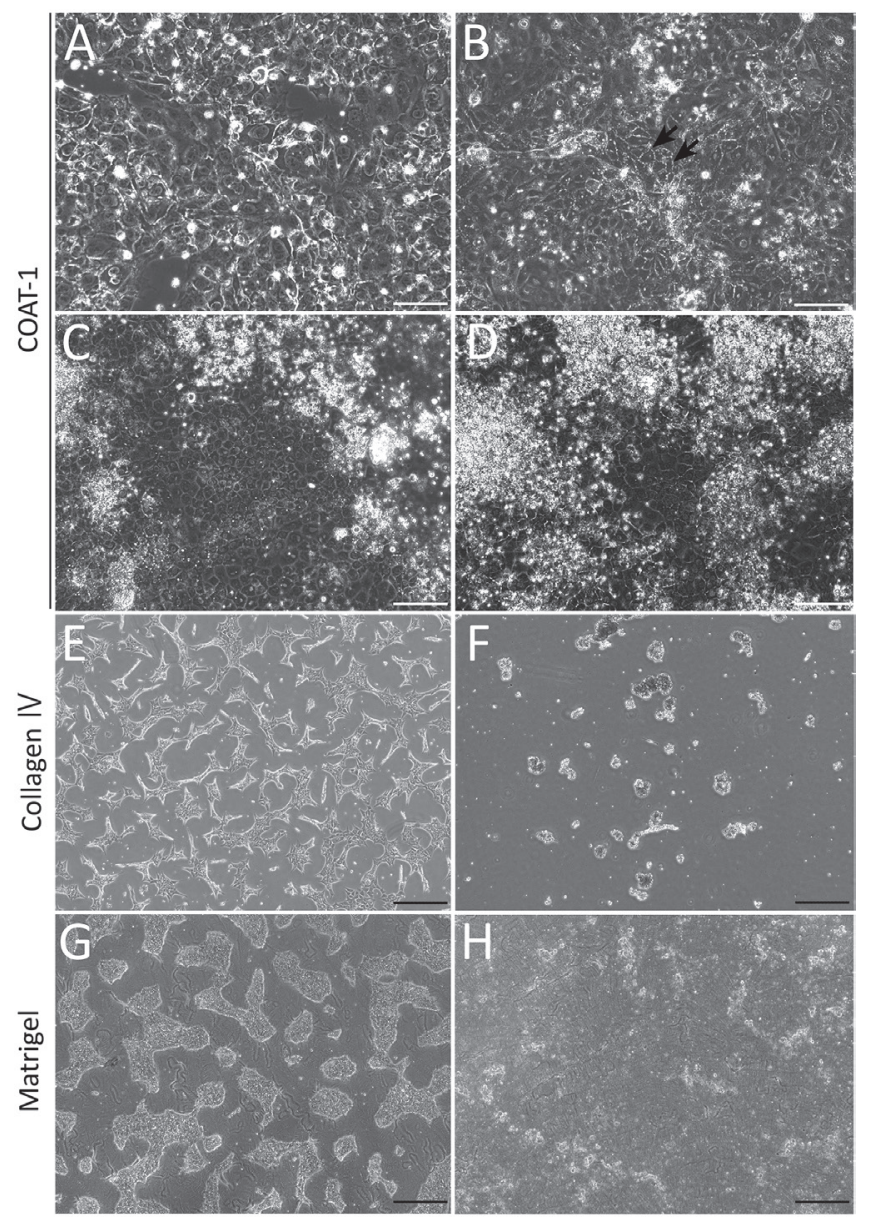

Figure 5. Phase-contrast microscopic image of human induced pluripotent stem cells (hiPSCs) cultured as single cells on three different types of coated dishes for epithelial cell differentiation. (A-D) Cells seeded on COAT-1-coated dishes. (A) hiPSCs were cultured in the DEF-CS medium for $48 \mathrm{~h}$. (B) hiPSCs cultured in an epithelial induction medium for seven days were morphologically similar to epithelial cells (arrows). (C) The density of the induced cells increased on post-induction day 14. (D) Induced cells were slightly detached on post-induction day 28. (E, F) Cells seeded in Collagen IV-coated dishes. (E) hiPSCs adhering to the bottom of the dish after $12 \mathrm{~h}$ of seeding before induction. (F) hiPSCs detached from the bottom of the dish after $24 \mathrm{~h}$ of seeding before induction. (G, H) Cells seeded in Matrigel-coated dishes. (G) hiPSCs adhered to the bottom of the dish after $48 \mathrm{~h}$ of seeding. (H) Induced cells detached from the bottom of the dish 6 days after replacement of the DEF-CS medium with the epithelial induction medium. White scale bars, $100 \mu \mathrm{m}$; black scale bars, $500 \mu \mathrm{m}$. 


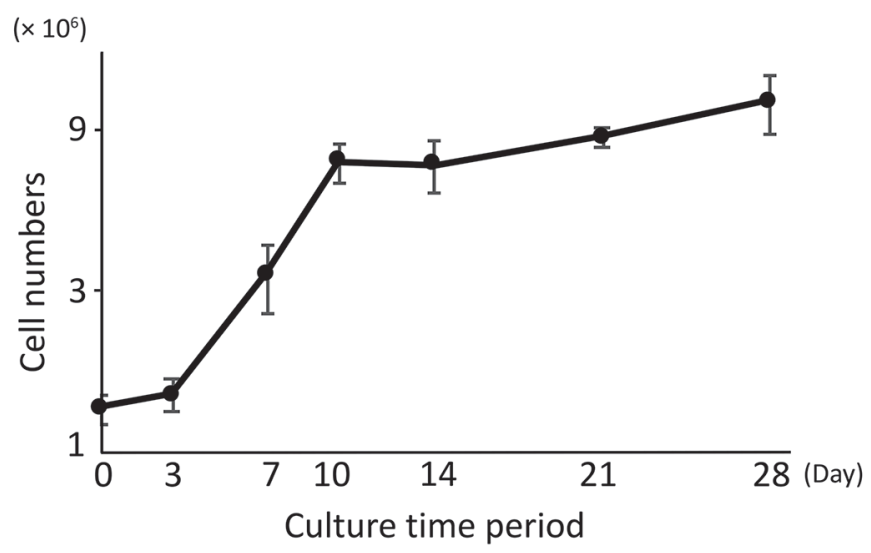

Figure 6. Proliferation potential of cells induced from human induced pluripotent stem cells cultured as single cells in epithelial induction medium for 28 days. The cells were counted using a cell counter model R1 (Olympus) on the indicated days. The induced cells proliferated in a linear manner from post-induction day 3 to 10 . Data are presented as mean $\pm \mathrm{SD}(\mathrm{n}=3)$. on day 28 increased by 1.5 -fold compared to that on day 10 (Fig. 6).

\section{Characteristics of induced cells derived from hiPSCs cultured as sin- gle cells during epithelial cell differentiation \\ Real-time PCR}

The mRNA expression levels of genes encoding pluripotency marker (OCT3/4), epithelial markers (P63,CK14, and CK18), and cell adhesion molecule markers (cadherin 1; $C D H 1$ and claudin 1 ; $C L D N 1$ ) in the induced cells were determined via the $\Delta \Delta \mathrm{Ct}$ method (Fig. 7). OCT3/4 mRNA was expressed on day 3; however, the expression was downregulated on day 7. $C K 18$ mRNA expression was upregulated by days 3-7, prior to $P 63$ and $C K 14$ upregulation. $P 63$ expression was progressively upregulated after day 7 , and $C K 14$ expression was upregulated on day 21 , followed by an upregulated expression of $P 63$. Furthermore, CLDN1 expression was progressively upregulated after day 21 . $\mathrm{CDH} 1$ expression was slightly downregulated on day 28 compared to that on days 3-21. The experiments were conducted in triplicate. The expression patterns of these markers displayed similar trends. Genes encoding pluripotency, epithelial, and cell adhesion molecule markers were examined using RNA extracted from hiPSC-derived NCCs as the negative control.

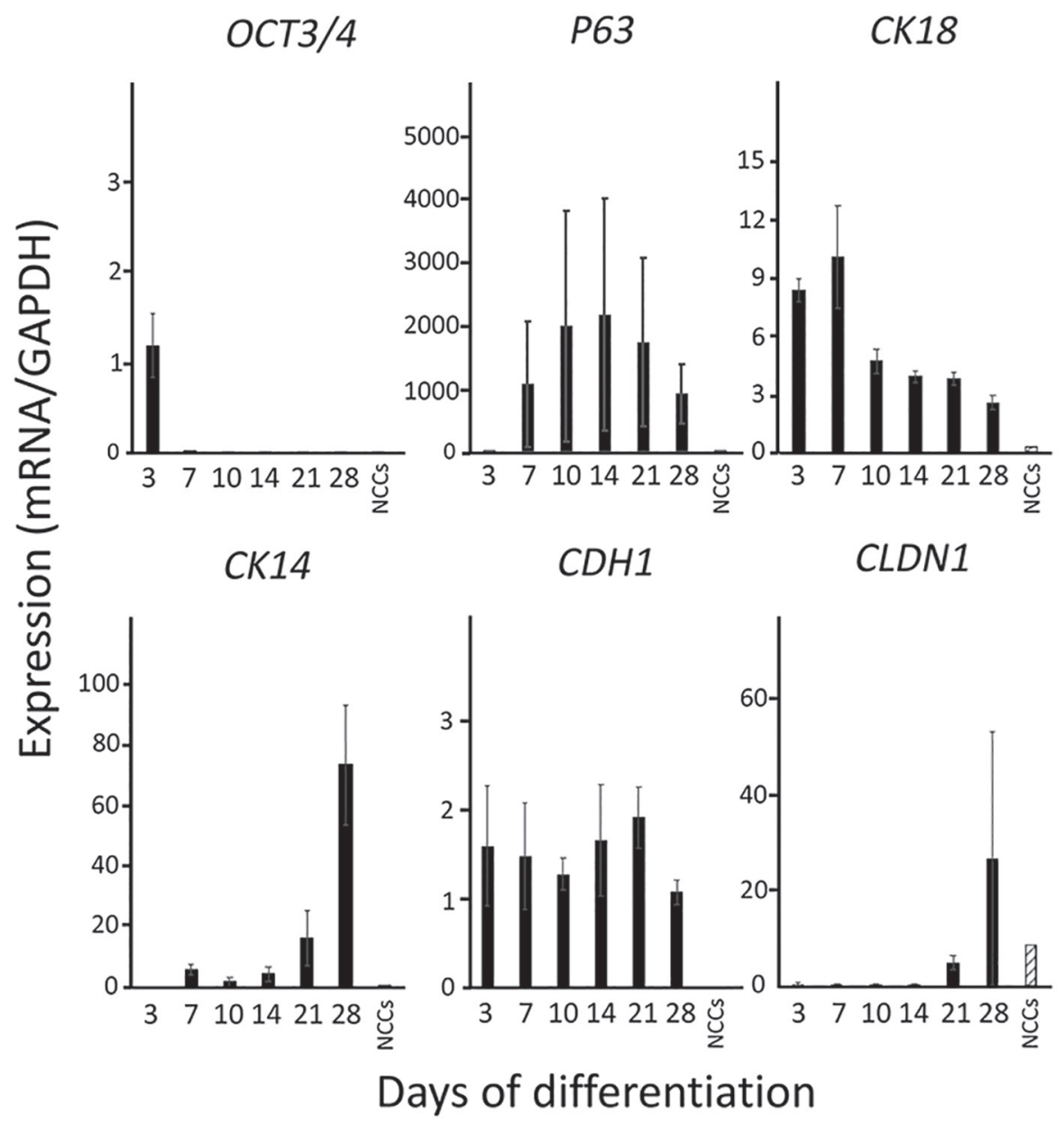

Figure 7. Quantification of the expression of pluripotency and epithelial marker genes in cells induced from human induced pluripotent stem cells cultured as single cells on days $3,7,10,14,21$, and 28 after epithelial induction as evaluated using real-time PCR. Pluripotency marker $O C T 3 / 4$ expression was downregulated; in contrast, expression levels of epithelial cell markers P63, CK18, and CK14 and cell adhesion markers $C D H 1$ and $C L D N 1$ were upregulated during epithelial induction. Neural crest cells were used as the negative control. Data are presented as mean \pm SD of triplicate experiments. 
Taku Futenma et al.: Epithelial Cells Derived from hiPSCs Cultured as Single Cells

Table 2. Expression profiling of adhesion molecule genes

\begin{tabular}{clccc}
\hline \multirow{2}{*}{ Symbol } & \multirow{2}{*}{ Name } & \multicolumn{2}{c}{ Relative Expression } & \multirow{2}{*}{$\begin{array}{c}\text { Accession } \\
\text { Number }\end{array}$} \\
\cline { 3 - 4 } & & Day 14 & Day 28 & NM_01529 \\
ICOSLG & Inducible T-cell co-stimulator ligand & 2.9 & 10.3 & NM_181351 \\
NCAM1 & Neural cell adhesion molecule 1 & 4.7 & 164.7 & NM_002997 \\
SDC1 & Syndecan 1 & 4.0 & 29.9 & .
\end{tabular}

CK18

day 3 day 14 day 28

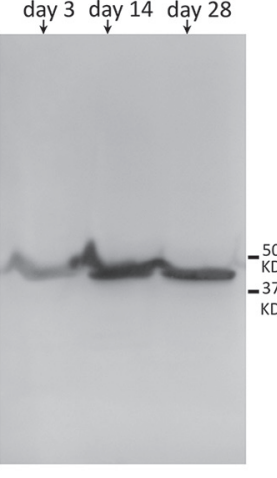

P63 day $_{\downarrow} 3$ day 14 day 28

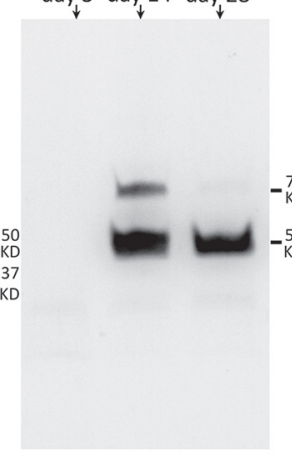

GAPDH
CK14
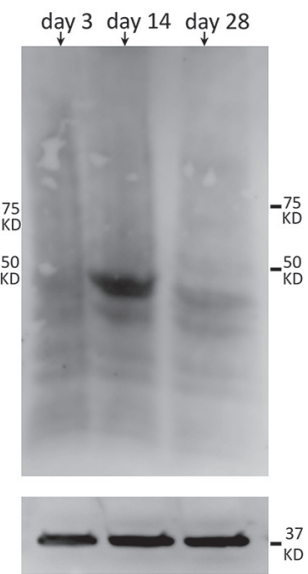

Figure 8. Immunoblots of epithelial marker proteins in cells on post-induction days 3,14 , and 28 during epithelial differentiation. GAPDH was used as the loading control.

\section{Expression profiling of genes encoding cell adhesion molecules}

The expression of 88 cell adhesion molecule-related genes using the primer array was examined. The differences in gene expression between induced cells on days 14 and 28 were compared. Furthermore, genes encoding adhesion molecules with $>2$-fold differences in expression levels on days 14 and 28 were selected and further investigated using real-time PCR. The expression levels of the three selected genes (inducible T-cell co-stimulator ligand ICOSLG, neural cell adhesion molecule 1 NCAMI, and syndecan $1 S D C 1$ ) on day 28 were $>2$-fold compared to those observed on day 14 (Table 2).

\section{Western blotting}

Epithelial marker protein expression was assessed via western blotting. CK18 expression was detected on day 3 and was remarkably expressed on days 14 and 28. P63 expression was detected on days 14 and 28. CK14 expression was only detected on day 14 (Fig. 8).

\section{Immunocytochemistry}

Immunocytochemistry was performed to determine the proportion of P63-, CK14-, and CK18-positive cells. CK18 expression was detected on day 7 of induction (Fig. 9A), whereas P63 and CK14 expression levels were detected on day 14 (Fig. 9B, C). The proportion of CK18-positive cells on day 7 was $48.0 \%$; on day 14 , the proportion of P63-positive cells was $67.4 \%$, and that of CK14-positive cells was $18.9 \%$.

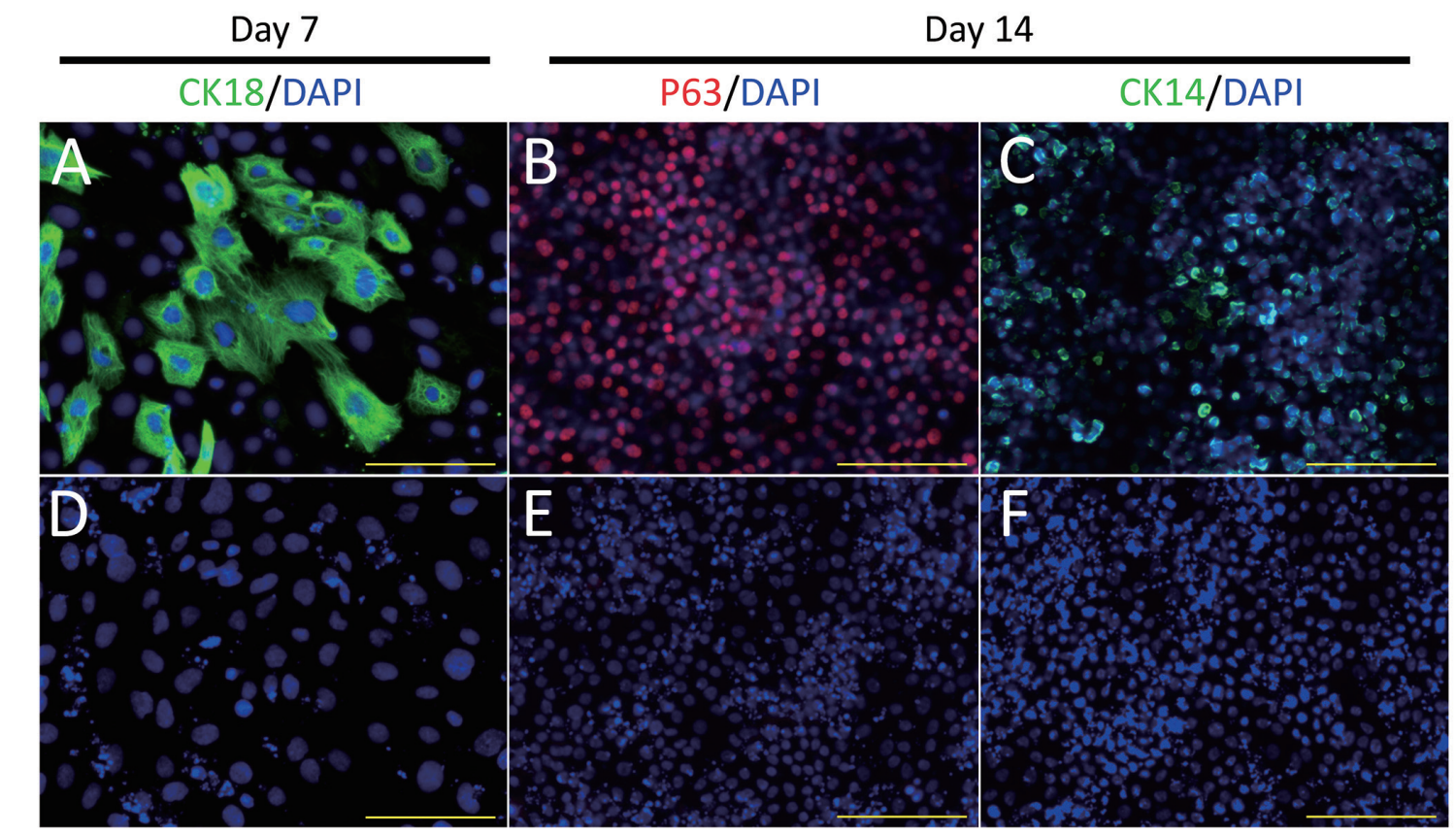

Figure 9. Immunocytochemistry of epithelial marker proteins in cells on post-induction days 7 and 14 during epithelial cell differentiation. (A) CK18 was detected on post-induction day 7 in hiPSCs. (B, C) P63 and CK14 were detected on post-induction day 14 in hiPSCs. The induced cells were not stained with normal mouse $\operatorname{IgG}(\mathrm{D}, \mathrm{F})$ and rabbit $\operatorname{IgG}(\mathrm{E})$ as isotype controls. The cells on post-induction day 14 (B, C, E, and F) were denser than those on day 7 (A, D). Overlaid images of DAPI-stained slides are shown. Scale bars, $100 \mu \mathrm{m}$. 


\section{Discussion}

In this study, we evaluated the feasibility of growing hiPSCs as single-cell derived, feeder-free cultures and investigated whether hiPSCs cultured as single cells differentiated into ectodermal-epithelial cells. Results showed that single cell-derived hiPSCs cultured in an epithelial induction medium supplemented with RA, BMP4, and N2 displayed a cobblestone-like morphology and exhibited key characteristics of ectodermal-epithelial cells in vitro.

The hiPSC line 253G1 cultured in colonies on MEFs was transferred and cultured as single cells using the DEF-CS medium and the accompanying coating material COAT-1. The hiPSCs cultured as single cells expressed pluripotency markers similar to those using a conventional colony culture method with MEFs. PCR revealed that hiPSCs cultured from single cells expressed $O C T 3 / 4, S O X 2, K L F 4$, and $c-M Y C$ at levels comparable to those present in colonies on MEF. Maintenance of pluripotency is governed by a set of transcription factors primarily involving $O C T 3 / 4, S O X 2$, and $N A N O G$ in $\mathrm{ESCs}^{48)}$. Our findings indicated that hiPSCs cultured as single cells retained their pluripotency.

Feeder cells may contribute to xenogeneic contamination and lot-tolot variability, impacting the final results of culturing ${ }^{49)}$. The direct differentiation of hiPSCs using defined chemical components is preferable. Therefore, we investigated whether hiPSCs cultured as single cells could be directly differentiated into ectodermal-epithelial cells, as per previously reported protocols for hPSCs cultured in colonies ${ }^{46,50}$, wherein media supplemented with $1 \mu \mathrm{M} \mathrm{RA}, 25 \mathrm{ng} / \mathrm{ml} \mathrm{BMP} 4$, and $1 \mathrm{X} \mathrm{N} 2$, were used. We found that these cells could differentiate.

Epithelial development is characterized by the expression of specific markers. The body surface is first covered by a single layer of basal epithelial cells during fetal development. This primitive epithelium activates a differentiation program leading to stratification during development; CK18-positive cells in the primitive epithelium are substituted with CK14-positive basal epithelial cells. Furthermore, P63 regulates the development of the stratified epithelia and is required for the commitment of PSCs to CK14-positive stratified epithelial cells ${ }^{50-52)}$. Our results indicated similar patterns with normal stratified epithelial development and corroborated previous reports of PSC differentiation into the ectodermal-epithelial lineage ${ }^{50,52)}$. Furthermore, our real-time PCR data indicated that CLDN1 expression, a component of tight junctions and a crucial factor for epithelial development ${ }^{53)}$, peaked on post-induction day 28.

We suggest that the mechanism underlying epithelial differentiation is as follows; BMP4 in the epithelial induction medium plays a critical role in ectodermal differentiation and directly activates $\Delta \mathrm{Np} 63$ (an isoform of P63, a transcription factor necessary for the maintenance of regenerative epithelia) ${ }^{50-52,54)}$. Furthermore, the early administration of RA upregulates $\triangle \mathrm{Np} 63$ expression and suppresses neural differentiation. Upregulated expression of $\Delta \mathrm{Np} 63$ subsequently and directly activates the CK14 promoter ${ }^{50,52)}$.

However, previous studies have reported that BMP4 induces the epithelial-mesenchymal transition (EMT) ${ }^{55,56)}$, while simultaneously inducing epidermal differentiation. We noticed the upregulation of cell adhesion markers associated with the EMT, namely ICOSLG, NCAM1, and $S D C 1^{57-59)}$, in induced cells on post-induction day 28 rather than on day 14. Our real-time PCR analyses indicated that $C D H 1$ expression was downregulated on post-induction day 28 , concurrent with a previous report which stated that $N C A M 1$ expression was upregulated and $C D H 1$ expression was downregulated during EMT progression ${ }^{57)}$.

We also found that the cells on post-induction day 28 were negative for CK14 expression, although this protein was detected on post-induction day 14, different from the results of the real-time PCR results. We attributed this to the presence of extensive disulfide cross-linking of keratins that yields insoluble proteins ${ }^{60)}$.

One limitation of this study is that only one hiPSC line, 253G1, was used. It is necessary to differentiate several hiPSC lines cultured as single cells into ectodermal-epithelial cells, as the epigenetic memory of their original phenotypes may limit their differentiation potential ${ }^{61,62)}$.

In conclusion, this study demonstrated the derivation of ectodermal-epithelial cells from hiPSCs cultured as single cells in a simple manner and found that hiPSCs from single-cell derived cultures maintain their pluripotency and differentiation potential. To the best of our knowledge, this is the first to report of the differentiation of passaged hiPSCs expanded as single cells into ectodermal-epithelial cells. The combination of this single cell-based culture method for hiPSCs with an ectodermal-epithelial differentiation protocol may facilitate the largescale generation of epithelial cells in regenerative therapy research and their subsequent applications. Further studies are needed to analyze the molecular-level events related to odontogenic potential and determine the optimal epithelial cell differentiation period for use in tooth regeneration studies.

\section{Acknowledgments}

This work was supported by JSPS KAKENHI Grant Number JP16K11703. We would like to thank Editage (www.editage.com) for English language editing.

\section{Conflict of Interests}

The authors have declared that no COI exsists.

\section{References}

1. Shen S, Wang S, He Y, Hu H, Yao B and Zhang Y. Regulation of bone morphogenetic protein 4 on epithelial tissue. J Cell Commun Signal 14: 283-292, 2020

2. Honda H. The world of epithelial sheets. Dev Growth Differ 59: 306-316, 2017

3. Hosoya A, Kwak S, Kim EJ, Lunny DP, Lane EB, Cho SW and Jung HS. Immunohistochemical localization of cytokeratins in the junctional region of ectoderm and endoderm. Anat Rec (Hoboken) 293: 1864-1872, 2010

4. Gilbert SF. Developmental biology. 8th ed. Sinauer Associates Inc, 2006.

5. Owaki T, Shimizu T, Yamato M and Okano T. Cell sheet engineering for regenerative medicine: current challenges and strategies. Biotechnol J 9: 904-914, 2014

6. Ntege EH, Sunami H and Shimizu Y. Advances in regenerative therapy: A review of the literature and future directions. Regen Ther 14: 136-153, 2020

7. Gilpin SE, Charest JM, Ren X, Tapias LF, Wu T, Evangelista-Leite D, Mathisen DJ and Ott HC. Regenerative potential of human airway stem cells in lung epithelial engineering. Biomaterials 108: 111-119, 2016

8. Inoie M and Ozawa Y. Autologus cultured epidermis: industrialization of regenerative medicine. Folia Pharmacol Jpn 137: 150-153, 2011

9. Matsumura H, Matsushima A, Ueyama M and Kumagai N. Application of the cultured epidermal autograft "JACE ${ }^{\circledR}$ " for treatment of severe burns: Results of a 6-year multicenter surveillance in Japan. Burns 42: 769-776, 2016 
10. Oie Y and Nishida K. Regenerative medicine for the cornea. Biomed Res Int 2013: 428247, 2013

11. Oie $\mathrm{Y}$ and Nishida K. Corneal regenerative medicine. Regen Ther 5: 40-45, 2016

12. Murakami D, Yamato M, Nishida K, Ohki T, Takagi R, Yang J, Namiki $\mathrm{H}$ and Okano T. Fabrication of transplantable human oral mucosal epithelial cell sheets using temperature-responsive culture inserts without feeder layer cells. J Artif Organs 9: 185-191, 2006

13. Binder S, Krebs I, Hilgers RD, Abri A, Stolba U, Assadoulina A, Kellner L, Stanzel BV, Jahn and Feichtinger H. Outcome of transplantation of autologous retinal pigment epithelium in age-related macular degeneration: a prospective trial. Invest Ophthalmol Vis Sci 45: 4151-4160, 2004

14. van Meurs JC, ter Averst E, Hofland LJ, van Hagen PM, Mooy CM, Baarsma GS, Kuijpers RW, Boks T and Stalmans P. Autologous peripheral retinal pigment epithelium translocation in patients with subfoveal neovascular membranes. Br J Ophthalmol 88: 110-113, 2004

15. Mandai M, Watanabe A, Kurimoto Y, Hirami Y, Morinaga C, Daimon T, Fujihara M, Akimaru H, Sakai N, Shibata Y, Terada M, Nomiya Y, Tanishima S, Nakamura M, Kamao H, Sugita S, Onishi A, Ito T, Fujita K, Kawamata S, Go MJ, Shinohara C, Hata KI, Sawada M, Yamamoto M, Ohta S, Ohara Y, Yoshida K, Kuwahara J, Kitano Y, Amano N, Umekage M, Kitaoka F, Tanaka A, Okada C, Takasu N, Ogawa S, Yamanaka S and Takahashi M. Autologous induced stem-cell-derived retinal cells for macular degeneration. N Engl J Med 376: 1038-1046, 2017

16. van Meurs JC and Van Den Biesen PR. Autologous retinal pigment epithelium and choroid translocation in patients with exudative age-related macular degeneration: short-term follow-up. Am J Ophthalmol 136: 688-695, 2003

17. Heussen FM, Fawzy NF, Joeres S, Lux A, Maaijwee K, Meurs JC, Kirchhof B and Joussen AM. Autologous translocation of the choroid and RPE in age-related macular degeneration: 1-year follow-up in 30 patients and recommendations for patient selection. Eye (Lond) 22: 799-807, 2008

18. van Zeeburg EJ, Maaijwee KJ, Missotten TO, Heimann $H$ and van Meurs JC. A free retinal pigment epithelium-choroid graft in patients with exudative age-related macular degeneration: results up to 7 years. Am J Ophthalmol 153: 120-127, 2012

19. Falkner-Radler CI, Krebs I, Glittenberg C, Povazay B, Drexler W, Graf A and Binder S. Human retinal pigment epithelium (RPE) transplantation: outcome after autologous RPE-choroid sheet and RPE cell-suspension in a randomised clinical study. Br J Ophthalmol 95: 370-375, 2011

20. Iwatsuki S, Honda MJ, Harada H and Ueda M. Cell proliferation in teeth reconstructed from dispersed cells of embryonic tooth germs in a three-dimensional scaffold. Eur J Oral Sci 114: 310-317, 2006

21. Nakao K, Morita R, Saji Y, Ishida K, Tomita Y, Ogawa M, Saitoh M, Tomooka Y and Tsuji T. The development of a bioengineered organ germ method. Nat Methods 4: 227-230, 2007

22. Ikeda E, Morita R, Nakao K, Ishida K, Nakamura T, Takano-Yamamoto T, Ogawa M, Mizuno M, Kasugai S and Tsuji T. Fully functional bioengineered tooth replacement as an organ replacement therapy. Proc Natl Acad Sci U S A 106: 13475-13480, 2009

23. Sumita Y, Honda MJ, Ohara T, Tsuchiya S, Sagara H, Kagami H and Ueda M. Performance of collagen sponge as a 3-D scaffold for tooth-tissue engineering. Biomaterials 27: 3238-3248, 2006
24. Takahashi K and Yamanaka S. Induction of pluripotent stem cells from mouse embryonic and adult fibroblast cultures by defined factors. Cell 126: 663-676, 2006

25. Takahashi K, Tanabe K, Ohnuki M, Narita M, Ichisaka T, Tomoda $\mathrm{K}$ and Yamanaka S. Induction of pluripotent stem cells from adult human fibroblasts by defined factors. Cell 131: 861-872, 2007

26. de Peppo GM, Marcos-Campos I, Kahler DJ, Alsalman D, Shang L, Vunjak-Novakovic G and Marolt D. Engineering bone tissue substitutes from human induced pluripotent stem cells. Proc Natl Acad Sci U S A 110: 8680-8685, 2013

27. Haase A, Olmer R, Schwanke K, Wunderlich S, Merkert S, Hess C, Zweigerdt R, Gruh I, Meyer J, Wagner S, Maier LS, Han DW, Glage S, Miller K, Fischer P, Schöler HR and Martin U. Generation of induced pluripotent stem cells from human cord blood. Cell Stem Cell 5: 434-441, 2009

28. Toriumi T, Takayama N, Murakami M, Sato M, Yuguchi M, Yamazaki Y, Eto K, Otsu M, Nakauchi H, Shirakawa T, Isokawa K and Honda MJ. Characterization of mesenchymal progenitor cells in the crown and root pulp of primary teeth. Biomed Res 36: 31-45, 2015

29. Lukovic D, Artero Castro A, Delgado AB, Bernal Mde L, Luna Pelaez N, Díez Lloret A, Perez Espejo R, Kamenarova K, Fernández Sánchez L, Cuenca N, Cortón M, Avila Fernandez A, Sorkio A, Skottman H, Ayuso C, Erceg S and Bhattacharya SS. Human iPSC derived disease model of MERTK-associated retinitis pigmentosa. Sci Rep 5: 12910, 2015

30. Mathur A, Loskill P, Shao K, Huebsch N, Hong S, Marcus SG, Marks N, Mandegar M, Conklin BR, Lee LP and Healy KE. Human iPSC-based cardiac microphysiological system for drug screening applications. Sci Rep 5: 8883, 2015

31. Yamanaka S. Pluripotent stem cell-based cell therapy-promise and challenges. Cell Stem Cell 27: 523-531, 2020

32. Nakagawa M, Taniguchi Y, Senda S, Takizawa N, Ichisaka T, Asano K, Morizane A, Doi D, Takahashi J, Nishizawa M, Yoshida Y, Toyoda T, Osafune K, Sekiguchi K and Yamanaka S. A novel efficient feeder-free culture system for the derivation of human induced pluripotent stem cells. Sci Rep 4: 3594, 2014

33. Martin MJ, Muotri A, Gage F and Varki A. Human embryonic stem cells express an immunogenic nonhuman sialic acid. Nat Med 11: 228-232, 2005

34. Chen YH and Pruett-Miller SM. Improving single-cell cloning workflow for gene editing in human pluripotent stem cells. Stem Cell Res 31: 186-192, 2018

35. Chen KG, Mallon BS, Hamilton RS, Kozhich OA, Park K, Hoeppner DJ, Robey PG and McKay RD. Non-colony type monolayer culture of human embryonic stem cells. Stem Cell Res 9: 237-248 2012

36. Jeon K, Park K and Jetten AM. Efficient Neural differentiation using single-cell culture of human embryonic stem cells. J Vis Exp 155: 10,2020

37. Watanabe $K$, Ueno M, Kamiya D, Nishiyama A, Matsumura M, Wataya T, Takahashi JB, Nishikawa S, Nishikawa S, Muguruma K and Sasai Y. A ROCK inhibitor permits survival of dissociated human embryonic stem cells. Nat Biotechnol 25: 681-686, 2007

38. Emre N, Vidal JG, Elia J, O'Connor ED, Paramban RI, Hefferan MP, Navarro R, Goldberg DS, Varki NM, Marsala M and Carson CT. The ROCK inhibitor Y-27632 improves recovery of human embryonic stem cells after fluorescence-activated cell sorting with multiple cell surface markers. PLoS One 5: e12148, 2010 
39. Gao X, Yourick JJ and Sprando RL. Generation of nine induced pluripotent stem cell lines as an ethnic diversity panel. Stem Cell Res 31: 193-196, 2018

40. Okamoto S, Amaishi Y, Maki I, Enoki T and Mineno J. Highly efficient genome editing for single-base substitutions using optimized ssODNs with Cas9-RNPs. Sci Rep 9: 4811, 2019

41. Asplund A, Pradip A, van Giezen M, Aspegren A, Choukair H, Rehnstrom M, Jacobsson S, Ghosheh N, El Hajjam D, Holmgren S, Larsson S, Benecke J, Butron M, Wigander A, Noaksson K, Sartipy P, Björquist P, Edsbagge J and Küppers-Munther B. One standardized differentiation procedure robustly generates homogenous hepatocyte cultures displaying metabolic diversity from a large panel of human pluripotent stem cells. Stem Cell Rev 12: 90-104, 2016

42. Moreau T, Evans AL, Vasquez L, Tijssen MR, Yan Y, Trotter MW, Howard D, Colzani M, Arumugam M, Wu WH, Dalby A, Lampela R, Bouet G, Hobbs CM, Pask DC, Payne H, Ponomaryov T, Brill A, Soranzo N, Ouwehand WH, Pedersen RA and Ghevaert C. Largescale production of megakaryocytes from human pluripotent stem cells by chemically defined forward programming. Nat Commun 7 : 11208, 2016

43. Konagaya $\mathrm{S}$ and Iwata $\mathrm{H}$. Chemically defined conditions for longterm maintenance of pancreatic progenitors derived from human induced pluripotent stem cells. Sci Rep 9: 640, 2019

44. Säljö K, Barone A, Vizlin-Hodzic D, Johansson BR, Breimer ME, Funa $\mathrm{K}$ and Teneberg $\mathrm{S}$. Comparison of the glycosphingolipids of human-induced pluripotent stem cells and human embryonic stem cells. Glycobiology 27: 291-305, 2017

45. Nakagawa M, Koyanagi M, Tanabe K, Takahashi K, Ichisaka T, Aoi T, Okita K, Mochiduki Y, Takizawa N and Yamanaka S. Generation of induced pluripotent stem cells without Myc from mouse and human fibroblasts. Nat Biotechnol 26: 101-106, 2008

46. Cai J, Zhang Y, Liu P, Chen S, Wu X, Sun Y, Li A, Huang K, Luo R, Wang L, Liu Y, Zhou T, Wei S, Pan G and Pei D. Generation of tooth-like structures from integration-free human urine induced pluripotent stem cells. Cell Regen 2: 6, 2013

47. Kawano E, Toriumi T, Iguchi S, Suzuki D, Sato S and Honda M. Induction of neural crest cells from human dental pulp-derived induced pluripotent stem cells. Biomed Res 38, 135-147, 2017

48. Chambers I and Tomlinson SR. The transcriptional foundation of pluripotency. Development 136: 2311-2322, 2009

49. Mallon BS, Park KY, Chen KG, Hamilton RS and McKay RD. Toward xeno-free culture of human embryonic stem cells. Int J Biochem Cell Biol 38: 1063-1075, 2006

50. Metallo CM, Ji L, de Pablo JJ and Palecek SP. Retinoic acid and bone morphogenetic protein signaling synergize to efficiently direct epithelial differentiation of human embryonic stem cells. Stem Cells 26: 372-380, 2008

51. Medawar A, Virolle T, Rostagno P, de la Forest-Divonne S, Gambaro K, Rouleau M and Aberdam D. DeltaNp63 is essential for epider- mal commitment of embryonic stem cells. PLoS One 3: e3441, 2008

52. Sakurai M, Hayashi R, Kageyama T, Yamato M and Nishida K. Induction of putative stratified epithelial progenitor cells in vitro from mouse-induced pluripotent stem cells. J Artif Organs 14: 58-66, 2011

53. Lopardo T, Lo Iacono N, Marinari B, Giustizieri ML, Cyr DG, Merlo G, Crosti F, Costanzo A and Guerrini L. Claudin-1 is a p63 target gene with a crucial role in epithelial development. PLoS ONE 3: e2715, 2008

54. Bakkers J, Hild M, Kramer C, Furutani-Seiki M and Hammerschmidt M. Zebrafish DeltaNp63 is a direct target of Bmp signaling and encodes a transcriptional repressor blocking neural specification in the ventral ectoderm. Dev Cell 2: 617-627, 2002

55. Huang HY, Chen SZ, Zhang WT, Wang SS, Liu Y, Li X, Sun X, Li YM, Wen B, Lei QY and Tang QQ. Induction of EMT-like response by BMP4 via up-regulation of lysyl oxidase is required for adipocyte lineage commitment. Stem Cell Res 10: 278-287, 2013

56. Richter A, Valdimarsdottir L, Hrafnkelsdottir HE, Runarsson JF, Omarsdottir AR, Ward-van Oostwaard D, Mummery C and Valdimarsdottir G. BMP4 promotes EMT and mesodermal commitment in human embryonic stem cells via SLUG and MSX2. Stem Cells 32: 636-648, 2014

57. Frame MC and Inman GJ. NCAM is at the heart of reciprocal regulation of E-cadherin- and integrin-mediated adhesions via signaling modulation. Dev Cell 15: 494-496, 2008

58. Liang J, Liu Z, Zou Z, Tang Y, Zhou C, Yang J, Wei X and Lu Y. The correlation between the immune and epithelial-mesenchymal transition signatures suggests potential therapeutic targets and prognosis prediction approaches in kidney cancer. Sci Rep 8: 6570, 2018

59. Yang Y, Tao X, Li CB and Wang CM. MicroRNA-494 acts as a tumor suppressor in pancreatic cancer, inhibiting epithelial-mesenchymal transition, migration and invasion by binding to SDC1. Int J Oncol 53: 1204-1214, 2018

60. Marcelo CL and Tong PS. Epidermal keratinocyte growth: changes in protein composition and synthesis of keratins in differentiating cultures. J Invest Dermatol 80: 37-44, 1983

61. Kim K, Doi A, Wen B, Ng K, Zhao R, Cahan P, Kim J, Aryee MJ, Ji H, Ehrlich LI, Yabuuchi A, Takeuchi A, Cunniff KC, Hongguang H, McKinney-Freeman S, Naveiras O, Yoon TJ, Irizarry RA, Jung N, Seita J, Hanna J, Murakami P, Jaenisch R, Weissleder R, Orkin SH, Weissman IL, Feinberg AP and Daley GQ. Epigenetic memory in induced pluripotent stem cells. Nature 467: 285-290, 2010

62. Polo JM, Liu S, Figueroa ME, Kulalert W, Eminli S, Tan KY, Apostolou E, Stadtfeld M, Li Y, Shioda T, Natesan S, Wagers AJ, Melnick A, Evans T and Hochedlinger K. Cell type of origin influences the molecular and functional properties of mouse induced pluripotent stem cells. Nat Biotechnol 28: 848-855, 2010 